\title{
Interstitial Insulin Concentrations Determine Glucose Uptake Rates but Not Insulin Resistance in Lean and Obese Men
}

\author{
Charles Castillo, Clifton Bogardus, Richard Bergman, * Pam Thuillez, and Stephen Lillioja \\ Clinical Diabetes and Nutrition Section, National Institutes of Diabetes, and Digestive and Kidney Diseases, National Institutes of \\ Health, Phoenix, Arizona 85016; and * Department of Physiology, University of Southern California, Los Angeles, California 90033
}

\begin{abstract}
Insulin action and obesity are both correlated with the density of muscle capillary supply in humans. Since the altered muscle anatomy in the obese might affect interstitial insulin concentrations and reduce insulin action, we have cannulated peripheral lymphatic vessels in lean and obese males, and compared peripheral lymph insulin concentrations with whole body glucose uptake during a euglycemic, hyperinsulinemic clamp. Lymph insulin concentrations in the lower limb averaged only $34 \%$ of arterial insulin concentrations during $150 \mathrm{~min}$ of insulin infusion. Obese subjects had the highest arterial $(P \leq 0.0001)$ and lymph insulin $(P<0.005)$ concentrations, but the lowest glucose uptake rates $(P<0.002)$. In contrast to the initial steep rise then plateau of arterial insulins, both lymph insulin and whole body glucose uptake rates rose slowly and did not consistently reach a plateau. In each individual, the glucose uptake closely correlated with peripheral lymphatic insulin concentrations (mean $r^{2}=0.95$ ). The coupling between glucose uptake and lymph insulin (glucose uptake/pmol insulin) was much steeper in lean subjects than in the obese $(P \leq 0.0001)$. These results indicate that even if insulin diffusion into tissues is rate limiting for insulin action, a tissue defect rather than an insulin diffusion defect causes insulin resistance in obese subjects. $(J$. Clin. Invest. 1994. 93:10-16.) Key words: lymph • lymphatic cannulation • euglycemic clamp • skeletal muscle • arterio-venous difference
\end{abstract}

\section{Introduction}

The reason some obese subjects develop insulin resistance is not known but several mechanisms have been proposed. An elevated supply of free fatty acids could reduce glucose oxidation $(1,2)$, leading to glycogen accumulation and downregulation of glycogen synthase ( 3 ), and failure to dispose of glucose in response to insulin. The mechanism is applicable, but the degree to which defects in glucose storage may develop chronically, and the fact that obesity seems to affect insulin action at supraphysiological insulin concentrations $(4,5)$ when free fatty acids are markedly suppressed, suggest that other mechanisms may also apply. Altered phospholipid content of cell membranes appears to be related to insulin resistance $(6,7)$,

This material has appeared in abstract form (1991. Diabetes. 40 [Suppl. 1]:241a).

Address correspondence to Dr. Stephen Lillioja, Department of Medicine, University of South Wales, Liverpool Hospital, Elizabeth Street, Liverpool, NSW 2170, Sydney, Australia.

Received for publication 23 September 1992 and in revised form 23 June 1993.

The Journal of Clinical Investigation, Inc.

Volume 93, January 1994, 10-16 and it is possible that overfeeding in the development of obesity might produce effects by the way lipids are incorporated in cell membranes. An increased supply of amylin cosecreted with insulin during overfeeding and weight gain might create an impairment of insulin action $(8,9)$. Finally, a reduced density of capillary supply and enlarged skeletal muscle fibers are related to obesity and insulin resistance (4). Previous studies have indicated that insulin concentrations are reduced in lymph compared with concentrations in arterial blood (1012 ), and we have postulated that physical changes in skeletal muscle might alter insulin action by affecting the equilibration of insulin in the tissues $(4,13)$. Studies in dogs by Yang et al. (14) and insulin kinetics studies in humans (15-18) have appeared to support this hypothesis.

The current studies show that insulin concentrations are indeed reduced in lymph and presumably in the rest of the interstitial space. However, the coupling between glucose uptake and insulin concentration is lower in the most obese, indicating that while capillary transport of insulin may be rate limiting for insulin action in any one individual (14), a cellular defect in insulin action and not a defect in insulin penetration to the interstitial space is the cause of insulin resistance in obese subjects.

\section{Methods}

Subjects. 13 healthy Caucasian males representing a wide range of obesity were studied. The results of lower limb lymph flow measurements in these subjects have been published in detail already (19). Subject G.F. from this prior publication is not used in the current analysis because of missing data. All subjects were nondiabetic as determined by a 75-g oral glucose tolerance test (20). Mean body mass index was $30.4 \mathrm{~kg} / \mathrm{m}^{2}$ ( ranging from 20.8 to $57.3 \mathrm{~kg} / \mathrm{m}^{2}$ ). Mean percent body fat from underwater weighing $(21,22)$ was $22.3 \%$ (ranging from 6.1 to 46.8\%; see Fig. 3). Mean age was $30.6 \mathrm{yr}$ (ranging from 21.2 to 36.6 $\mathrm{yr}$ ). Metabolic size (ms) ${ }^{1}$ is fat-free mass $+20 \mathrm{~kg}$ (c.f. reference 13).

Lymphatic cannulation. A recent publication has been devoted to a description of the lymphatic cannulation method (19). In brief, a fine catheter was prepared by heating the tip of a 5-in, 20-gauge polyurethane catheter (Arrow International, Reading, PA) and stretching it to a fine taper. The tip, at a diameter of $0.35-0.45 \mathrm{~mm}$, was then compatible with the diameter of lymphatic vessels. Lymphatic vessels were detected in the epifascial subcutaneous tissue of the leg $15 \mathrm{~cm}$ proximal to the medial malleolus, between the medial border of the tibia and the saphenous vein, after an injection of isosulphan blue into the pedal web spaces. The lymph vessels were cannulated by the Seldinger technique using 4-0 nylon and a 25 -gauge needle. Lymph was collected in a vented EDTA vacutainer tube, and the weight of tubes before and after lymph collection enabled the lymph volume to be calculated. Lymph was collected at 15-min intervals during the metabolic studies, and flow rates ranged from 0.34 to $4.96 \mathrm{ml} / \mathrm{h}$. In each subject the lymph vessels were cannulated the day before the metabolic study and a collecting tube was in place for $\sim 24 \mathrm{~h}$. During the metabolic procedure (see

1. Abbreviations used in this paper: A-V, arterio-venous; MS, metabolic size. 
below), the foot of the cannulated leg was placed in a warming box at $42^{\circ} \mathrm{C}$ with a venapulse VP-50 pneumatic compressor cuff (ACI Medical, Sun Valley, CA) applied to the forefoot. The latter gave pressure pulses at 3-s intervals to increase intrinsic lymphatic contractions. These measures were to increase lymph flow, without increasing metabolic demands $(23,24)$. The lymph collected in these studies is presumably from subcutaneous tissues of the ankle and forefoot and not from skeletal muscle.

Metabolic studies: euglycemic clamp. Glucose uptake was measured during a euglycemic clamp as previously described $(4,25)$, except that no priming dose of insulin was given. The following cannulation schedule was used: a central venous line for glucose, $3-\left[{ }^{3} \mathrm{H}\right]-$ glucose, and insulin infusions in the left antecubital vein; an arterial catheter in the right radial artery; a lymph cannula in the left lower extremity; a venous catheter in the right femoral vein with a thigh-high TED antiembolism stocking (Kendall Co., Manifield, MA) on that limb.

A primed continuous infusion of 3-[ $\left[{ }^{3} \mathrm{H}\right]$ glucose was commenced at $-120 \mathrm{~min}$ and continued for the duration of the test, which lasted 240 min from time 0 . At 0 min an infusion of purified pork insulin (Nordisk, Bethesda, MD) was commenced at an infusion rate of $290 \mathrm{pmol} /$ $\mathrm{m}^{2}$ body surface area per min and continued for $150 \mathrm{~min}$ and then abruptly stopped. The patient was observed for a further $90 \mathrm{~min}$. At $\sim 0 \mathrm{~min}$ an infusion of $20 \%$ glucose was commenced and the rate of its infusion varied to maintain euglycemia. The $20 \%$ dextrose contained trace amounts of 3-[ $\left.{ }^{3} \mathrm{H}\right]$ glucose according to the methods described by Finegood et al. and Bergman et al. $(26,27)$. The $20 \%$ glucose infusion was continued as needed for the $240 \mathrm{~min}$.

The arterial line was sampled for glucose, basally and at 5-min intervals to $240 \mathrm{~min}$, and was sampled for [ ${ }^{3} \mathrm{H}$ ] glucose and insulin at 10 -min intervals from 0 to $240 \mathrm{~min}$. The femoral venous line was sampled basally and at 10 -min intervals from 0 to $240 \mathrm{~min}$ for glucose and insulin. Lymph samples were collected at 15-min intervals for glucose and insulin.

Insulin concentrations in plasma and lymph were measured by a coated tube method using a radioassay analyzer (Concept 4; I.C.N., Horsham, PA ). 3- $\left[{ }^{3} \mathrm{H}\right]$ Glucose was measured as previously described by others (28) using perchloric acid to precipitate proteins.

Hot glucose infusion. The hot glucose infusion method was used in this study to minimize errors due to the weakness of the single compartment model $(26,27,29)$. Within experimental error the assumptions of the methods appear to have been met; hence, by paired $t$ test mean specific activity did not change from basal to insulin on, insulin on to insulin off, or basal to insulin off. Also, by paired $t$ test there was no significant difference between rate of dissapearance (Rd) from 3$\left[{ }^{3} \mathrm{H}\right]$ or exogenous infusion examining the $90-210$-min time period when the liver should be suppressed. This was also true if the two most insulin-resistant or four most insulin-resistant subjects were not included. The rate of glucose disappearance at any particular 10-min interval was calculated as the maximum of either Rd from $3-\left[{ }^{3} \mathrm{H}\right]-$ glucose analysis or the exogenous glucose infusion. This calculation has the advantage of providing a glucose uptake rate when there was incomplete hepatic suppression, such as in the first and last minutes of the studies. Furthermore, since ${ }^{3} \mathrm{H}$ and exogenous methods gave similar results, using both helps minimize random experimental error.

Statistical analyses. Data were smoothed before analysis using running means with care not to smooth over sharp transitions (such as when insulin was stopped at $150 \mathrm{~min}$ ). Data were analyzed using the programs of the Statistical Analysis System Institute (Cary, NC) including RSQUARE, CORR, and MEANS procedures. Lymph samples were collected at 15 -min intervals, and arterial insulin at 10-min intervals. Linear interpolations were used after smoothing to provide 5-min intervals and allow correlation of lymph insulin and glucose uptake. The regression of lymph insulin and glucose uptake was performed by repeatedly analyzing the relationship after lymph insulin values are moved to the left in Fig. 1 (but using one individual at a time) by 5-min increments. The best $r^{2}$ was taken as the best fit. The two most obese individuals had essentially no insulin action, and these regression pro- cedures were not meaningful (see Fig. 3 and legend). It was felt important to analyze the whole $240 \mathrm{~min}$ in one model to assess this lag, but the change in regression slope after $150 \mathrm{~min}$ (see Fig. 2, inset) meant that a more complex regression model was needed. The regression model had to allow for two straight lines that intercepted at a sharp point at a specific time. The form of the regression model was: $U=\beta_{0}$ $+\beta_{1} L+\beta_{2} \mathrm{Z}(\mathrm{L}-\mathrm{C})$, where $U$ is glucose uptake, $L$ is lymph insulin, $Z$ is 0 below $150 \mathrm{~min}$ and 1 above that time point, and $C$ is the value of $L$ at $150 \mathrm{~min}$. This regression produces straight lines that intercept at $C$, but $C$ is not necessarily the apogee of glucose uptake or lymph insulin. Such an analysis is described as piecewise or spline regression (30). For the regression analysis involving time the model used was: $U=\beta_{4}$ $+\beta_{5} L+\beta_{6} T$, where $U$ is glucose uptake, $L$ is lymph insulin, and $T$ is time point at which glucose uptake was measured. The results showed that the coefficient of the time variable was not significant in those subjects where the slope did not change at $150 \mathrm{~min}$.

\section{Results}

Arterial insulin concentrations rose rapidly and reached a plateau, and then rapidly declined when the insulin infusion was stopped (Fig. 1). The insulin concentrations in the most obese subjects stabilized higher $(P \leq 0.0001)$. By contrast, the lymph insulin concentration rose slowly after an initial delay and did not clearly reach a plateau. Again, the most obese had the highest values $(P<0.005)$. The mean lymph insulin averaged only $34 \%$ of the mean arterial insulins (range, 18-60\%) during the $2.5 \mathrm{~h}$ of insulin infusion, even taking account of the delays involved in lymph reaching the sampling site (see below). The ratio of lymph to arterial insulin did not vary with obesity $(P=0.6)$.

In Fig. 1, bottom, the rate of glucose uptake over time can be compared with the simultaneous insulin concentrations. The most obese two individuals had essentially no insulin action. The glucose uptake time course was very similar to that of the lymph insulin and markedly different from the time course of the arterial insulin concentration. This was true even though the lymph sampled is from the subcutaneous tissues of the medial ankle and forefoot. This suggests, not surprisingly, that insulin concentrations in lymph are more similar to those in the compartment from which insulin acts than are arterial insulin concentrations.

The correlation of insulin concentrations and glucose uptake values were assessed in each individual excluding the two individuals with essentially no insulin action. A regression of arterial insulin and glucose uptake was, as expected considering Fig. 1, rather poor (mean $r^{2}=0.15$; range, $0.0-0.37$ ). The regression of lymph insulin and glucose uptake was better ( mean $r^{2}, 0.48$; range, 0.09-0.74). However, the lymph insulin appeared to be delayed relative to glucose uptake (Fig. 1), and it was also apparent that the relationship changed in some individuals after the insulin infusion was stopped (Fig. 2). By introducing a lag time of $20 \mathrm{~min}$ between lymph insulin sampling, and allowing the relationship between glucose uptake and lymph insulin to change at $150 \mathrm{~min}$, the regression of these two variables improved markedly (mean $r^{2}=0.91$; range, 0.78-0.97). Finally, if each individual was allowed their own lag time (mean, $22 \mathrm{~min}$; range, 0-50 min), the relationship of lymph insulin and glucose uptake gave a mean $r^{2}$ of 0.95 (range, 0.91-0.995); i.e., 95\% of the variance in glucose uptake in an individual is explained by the variance in lymph insulin. These data indicate that insulin action in peripheral tissues is 


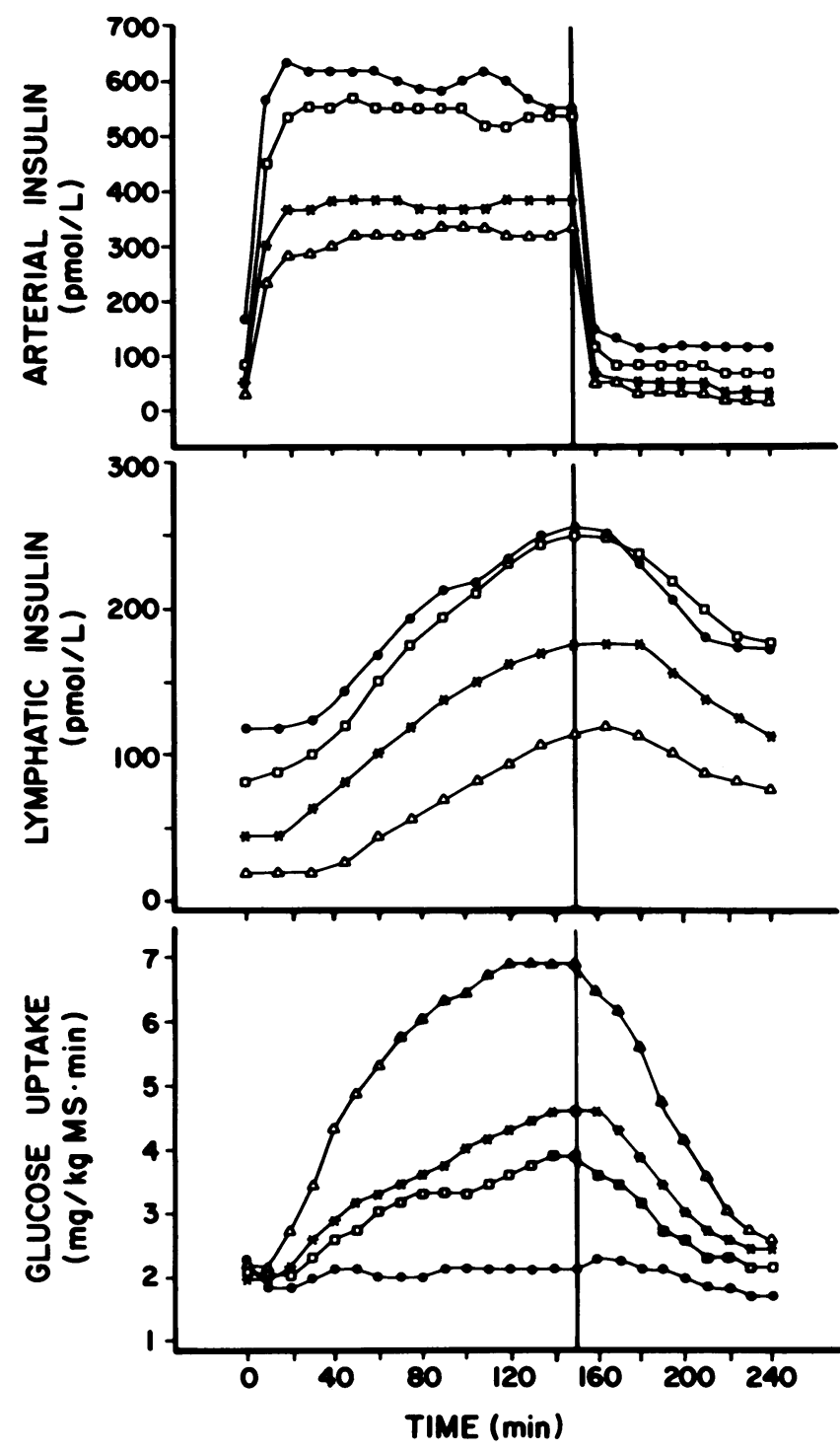

Figure 1. Arterial and lymphatic insulin concentrations during (150 $\mathrm{min})$ and after $(90 \mathrm{~min})$ the infusion of insulin into an antecubital vein at a rate of $290 \mathrm{pmol} / \mathrm{m}^{2}$ body surface area per min in 13 healthy nondiabetic Caucasian males. For convenience of presentation, the data are grouped by degree of obesity (percent body fat from densitometry [10]: $\triangle, \leq 12 \% ; *, 13-21 \% ; \square, 22-35 \% ; \bullet, \geq 36 \%$; compare Fig. 3, where data are presented for each individual). Dextrose (20\%) was infused to maintain euglycemia. The insulin concentrations in arterial plasma rapidly reached steady state and were higher in the most obese. Lymphatic insulin concentrations increased slowly and were in some cases still approaching steady state after $150 \mathrm{~min}$ but were also highest in the most obese. Glucose uptake showed a similar time course to the lymphatic insulin except that the most obese showed essentially no response, and the ranking in glucose uptake is the reverse of the insulin concentrations. Arterial insulin and glucose uptake were measured every $10 \mathrm{~min}$, and lymph insulin every $15 \mathrm{~min}$ during insulin infusion.

determined by a compartment with an insulin concentration closely related to the insulin concentration in lymph.

Lymph flow rate was correlated with percent body fat $(r$ $=0.75, P<0.004)$, but the lag time was not correlated with either obesity $(P=0.16)$ or lymph flow rate $(P=0.29)$. The flows averaged $1.84 \mathrm{ml} / \mathrm{h}$ or $0.46 \mathrm{ml} /$ specimen, and the volume of the catheter was $\sim 0.05 \mathrm{ml}$, so that transit time through the catheter was on average $1.6 \mathrm{~min}$, ranging from $50 \mathrm{~s}$ to $\sim 5 \mathrm{~min}$.

In some subjects there was a change in relationship of lymph insulin to glucose uptake after the 150 -min time point when the insulin infusion was stopped (Fig. 2, inset). In 7 of 11 subjects the slope was steeper and lower after $150 \mathrm{~min}$ than before, in 1 subject the slope was shallower and higher, and in 3 subjects it was not significantly different. This change in slope was not due to a change in the glucose-specific activity. Those three subjects without a change in slope were also the leanest, and the subject with the increase in slope was the fifth leanest.

The most likely explanation for this change in slope is that glucose uptake relative to insulin concentration is steadily decreasing throughout the test and this continues after the insulin infusion ceases. In Fig. 2 each data point is in chronological sequence. One could imagine in Fig. 2 a line that passes through the basal data point from subject 3 , for example, but is steeper than the upslope illustrated. As time proceeds the glucose uptake at a given insulin concentration falls further and further below this idealized line. When the lymph insulins begin to fall after stopping the insulin infusion, the glucose uptake continues to drop below this idealized line so that now insulin at $175 \mathrm{pmol} /$ liter, for example, is even less effective than it was $60 \mathrm{~min}$ before. This hypothesis is confirmed by an analysis in which the lymph curves are lagged as above, but instead of allowing the slope to change at $150 \mathrm{~min}$ the regression equation uses lymph insulin and time to predict glucose uptake (see Methods). The mean $r^{2}$ in this case was 0.94 , ranging from 0.84 to 0.994 (not affected if three leanest subjects who had neither a change in slope nor a significant time effect are not included). The sign of the coefficient of time was the same as on the change in slope. That is, if the slope becomes steeper after $150 \mathrm{~min}$ the coefficient for time in the regression is negative (time results in a decreased effect of insulin).

This time-dependent effect is not enough to explain the low slopes in insulin-resistant subjects. In Fig. 2 the slope without a time-dependent effect would have been $0.6 \mathrm{mg} / \mathrm{kg}$ MS per min higher for subject 5 at $150 \mathrm{~min}$ and $0.22 \mathrm{mg} / \mathrm{kg}$ MS per min higher for subject 6 at $150 \mathrm{~min}$.

There was a wide variation in the coupling of glucose uptake and lymph insulin, as shown in Fig. 2. That is, in some individuals there is little glucose uptake change in spite of a large change in lymph insulin, while in others a small change in insulin results in large changes in glucose uptake. This information is summarized in Fig. 3, where the slope of the initial glucose uptake relationship $(0-150 \mathrm{~min})$ is plotted against percent body fat. Clearly, the most obese have a lower coupling of glucose uptake to lymph insulin. Insulin resistance is usually assessed by the glucose uptake (in $\mathrm{mg} / \mathrm{min}$ ) during some time interval near the end of an insulin infusion. For comparison with such data, the initial slope of the glucose uptake/lymph insulin relationship in each individual was correlated with the glucose uptake during $0-150 \mathrm{~min}(r=0.88, P \leq 0.0001), 120-$ $150 \mathrm{~min}(r=0.92, P \leq 0.0001)$, and during $0-240 \mathrm{~min}(r$ $=0.90, P \leq 0.0001)$.

We have also compared the mean arterio-venous ( A-V differences and mean uptake rate of glucose over $150 \mathrm{~min}$ of insulin infusion (Fig. 4). Both values are highly correlated $(r$ $=0.88, P \leq 0.0001)$. It can be seen that in the most insulin-resistant subjects the percent A-V difference is quite small. In contrast the percent $\mathrm{A}-\mathrm{V}$ difference is high in the more sensi- 


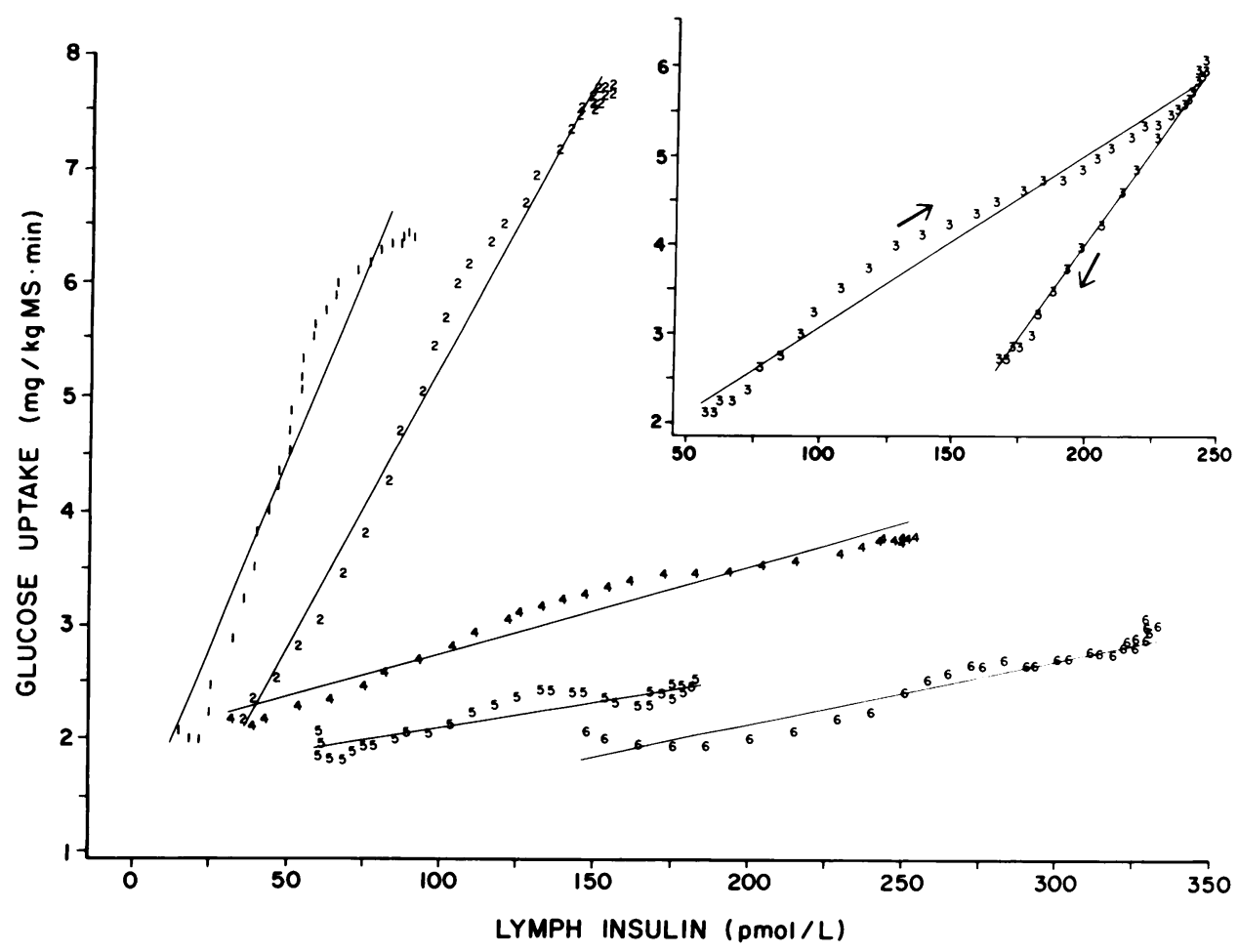

Figure 2. Correlation of whole body glucose uptake with peripheral lymphatic insulin concentrations. Only six individuals are shown to preserve clarity. For five individuals ( main figure) only the first 150 min (insulin infusion) is shown, and the variability in uptake/insulin coupling is demonstrated. Each data point is at 5-min intervals using linear interpolation because arterial values were collected at 10-min intervals and lymph at $15-\mathrm{min}$ intervals. The regression lines $(-)$ and data points (1-6) show the close correlation of glucose uptake and lymphatic insulin in each individual (mean $r^{2}$ $=0.95$ : range, $0.91-0.995)$. The inset shows the whole time course (150-min insulin infusion, $90-\mathrm{min}$ insulin infusion stopped) in one individual showing that after $150 \mathrm{~min}$ the correlation is also close but on a different and steeper line. In this subject in the inset, for example, glucose uptake $=1.15+(0.020$ $\times$ insulin ) below $150 \mathrm{~min}$; and glucose uptake $=1.15+(0.020 \times$ insulin $)+(0.025 \times[$ insulin -242$])$

above $150 \mathrm{~min}$, where the insulin at $150 \mathrm{~min}$ was $242 \mathrm{pmol} /$ liter $\left(r^{2}=0.99\right)$. If, instead. time is used as a variable the relationship becomes glucose uptake $=0.68+(0.028 \times$ insulin $)-(0.012 \times$ time $)$, where time is in minutes from the start of the test $\left(r^{2}=0.97\right)$. This suggests that after $90 \mathrm{~min}$ the glucose uptake is $1.1 \mathrm{mg} / \mathrm{kg}$ MS per min less than it would have been without a time-dependent effect. After $150 \mathrm{~min}$ the glucose uptake is $1.8 \mathrm{mg} / \mathrm{kg}$ MS per min less than it might have been and after $240 \mathrm{~min}, 2.9 \mathrm{mg} / \mathrm{kg}$ MS per min less than otherwise.

tive, leaner subjects, indicating that the flow rate is most limiting for glucose diffusion in sensitive individuals. The percent A-V difference of insulin across the leg averaged $19 \%$, but was not correlated with obesity $(P=0.8)$ or with glucose uptake ( $P$ $=0.6$ ).

\section{Discussion}

We have studied 13 young men of varying degrees of obesity to assess, both within and between individuals, the relationship of interstitial insulin concentrations and insulin action. The results show that lymph insulin concentrations are a good estimate of the concentration of insulin at the site where insulin exerts its action on glucose uptake. The supply of insulin to this compartment, however, is not the cause of any apparent insulin resistance in obese subjects. This is demonstrated by the fact that the most obese insulin-resistant subjects had the highest lymph insulin concentrations and these subjects also had the lowest coupling between glucose uptake and insulin concentrations in lymph. Hence, insulin resistance in obese subjects is not due to failure of insulin to reach its site of action but due to factors in the tissues themselves.

A "continuous" capillary endothelium is a significant barrier to free diffusion from blood into tissues such as skeletal muscle, adipose tissue, and skin $(31,32)$. The glycocalyx, the basement membrane, and the interstitium beyond the capillary contribute to reduced diffusion (33-35). Hence, gradients of insulin concentration from capillary to tissue are inevitable when plasma insulin concentrations change. It has been known for some time that insulin concentrations in the lymph of dogs are lower than, and do not fluctuate as widely as, simultaneous arterial and venous insulin concentrations (10-12). Hence, available evidence indicates that penetration of insulin to its site of action is delayed by the capillary wall in spite of transport or direct effects of insulin on macromolecular diffusion $(36,37)$.

In this study we have collected lymph that probably drains from subcutaneous tissues of the ankle and foot. It would have been preferable to sample lymph from skeletal muscle, the dominant site of insulin action in a study such as this (38). Lymphatics in skeletal muscle follow arterioles and venules and do not even accompany capillaries (39). Hence, it may be impossible to sample the interstitial fluid bathing muscle cells by sampling lymph. The lymph values here may, therefore, be no different from those of lymphatics draining a muscle, especially since the capillaries of skeletal muscle, adipose tissue, and skin are all similarly "continuous" $(31,32)$. It is not known if there are insulin gradients deep within the muscle interfiber clefts, and, therefore, it is difficult to even estimate what insulin concentrations are engulfing a muscle cell (compare reference 13). The good correlation of lymph insulin and whole body glucose uptake suggests the methodology must have been appropriate, however.

Studies of insulin kinetics, the first euglycemic clamps (15), indicated that insulin action in humans is significantly delayed relative to changes in arterial insulin, and modeling suggested that insulin was acting from some remote and slowly equilibrating compartment. Ex vivo studies have also shown a slow-onset insulin action relative to changes in arterial insulin (40). Furthermore, glucose uptake and lymph insulin have 


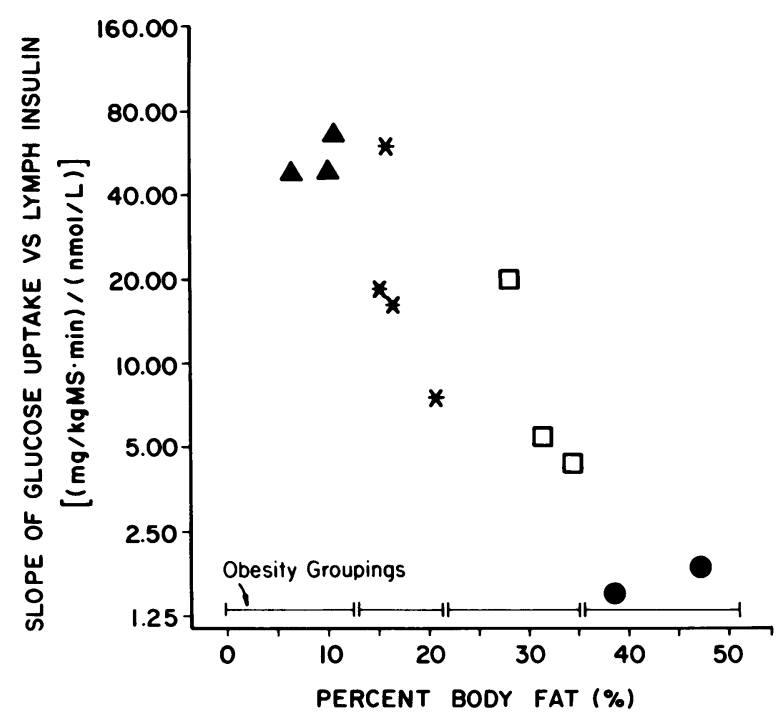

Figure 3. The initial slope of glucose uptake/lymph insulin relationship ( from Fig. 2) in all subjects vs. degree of obesity (percent body fat) $(r=-0.91, P \leq 0.0001)$. There is a wide variation in the coupling between insulin and glucose uptake depending on the degree of obesity (Note one observation is hidden. The observations at that point have values of slope 16.7 and $16.6[\mathrm{mg} / \mathrm{kg} \mathrm{MS}$ per $\mathrm{min}$ ]/[ $\mathrm{nmol} /$ liter] and percent fat of 16.1 and 16.4, respectively). In 11 individuals the slope was determined by optimizing the linear regression of glucose uptake and lymph insulin for the whole $240 \mathrm{~min}$ by allowing for a lag between insulin uptake and lymph insulin appearance, and by allowing the slope to change once. Two individuals (see Fig. 1) had essentially no insulin action and this procedure could not be performed meaningfully. For those two, the regression of glucose uptake and lymph insulin in the first $150 \mathrm{~min}$, with a 20-min lag of lymph insulin concentrations, provided the slope value that is plotted.

been shown to be correlated in dogs $(11,14)$. These and related findings and the demonstration of a correlation between reduced capillary density in $\mathrm{m}$. vastus lateralis (4) led us to postulate that reduced capillary density in the obese $(4,13)$ might result in altered tissue concentrations and an "apparent" insulin resistance. The studies of Yang et al. (14) in dogs lent further support to this view. Unless there are large gradients of insulin deep within the interfiber clefts in muscle that cannot be detected in this study, the current data refute this hypothesis.

Yang et al. (14) provided evidence that insulin penetration into tissue was rate limiting for insulin action in dogs. The current studies do not contradict this, but do demonstrate that penetration of insulin into the interstitium does not distinguish insulin-sensitive and insulin-resistance individuals, i.e., insulin penetration into tissues may be equally rate limiting in the lean and the obese. The large variation in the coupling of glucose uptake with lymph insulin and the correlation of this coupling with obesity indicates that tissue factors determine insulin resistance in obese humans.

An unexpected finding in this study was the change in slope of the relationship of glucose uptake and lymph insulin after the insulin infusion was stopped. The most likely explanation for this is a steady decline in insulin action from the very start of the infusion, and the time-dependent decrease in insulin effect could be demonstrated directly in a regression of glucose uptake with lymph insulin and time. An alternate explanation is that insulin acts from an even more remote compartment that is equilibrating slowly with the lymph compartment. This seems unlikely since the expected effect then would have been a greater persistence of insulin action rather than a reduction. Further studies will be needed to test this conclusion about the waning of insulin action since no previous studies in vivo are available to compare insulin action with insulin concentrations in a compartment close to the site of insulin action. The contribution of this time-dependent effect to insulin resistance may be small, however, compared with other factors reducing insulin action.

An important implication of the current studies relates to pulsatile insulin secretion (41-44). It is apparent that rapid fluctuations of insulin concentrations are so dampened as to be largely absent at the site of insulin action in the periphery. This damping of insulin fluctuations does not apply to the liver, however. The liver capillaries are discontinuous (31), and it is possible that the liver will be affected by fluctuations of insulin differently to the periphery $(43,44$, but compare reference 42$)$. It is possible, therefore, that sharply fluctuating insulin concentrations serve to selectively signal the liver and not the periphery.

Elegant studies by Laasko et al. and Baron et al. $(45,46)$ have demonstrated a reduced activation of lower limb blood flow in obese subjects in response to insulin. These are significant findings but still leave a critical question unanswered: Is the reduced blood flow a cause or an effect of insulin resistance? There is a strong correlation between A-V glucose difference and whole body glucose uptake in our data (Fig. 4), and

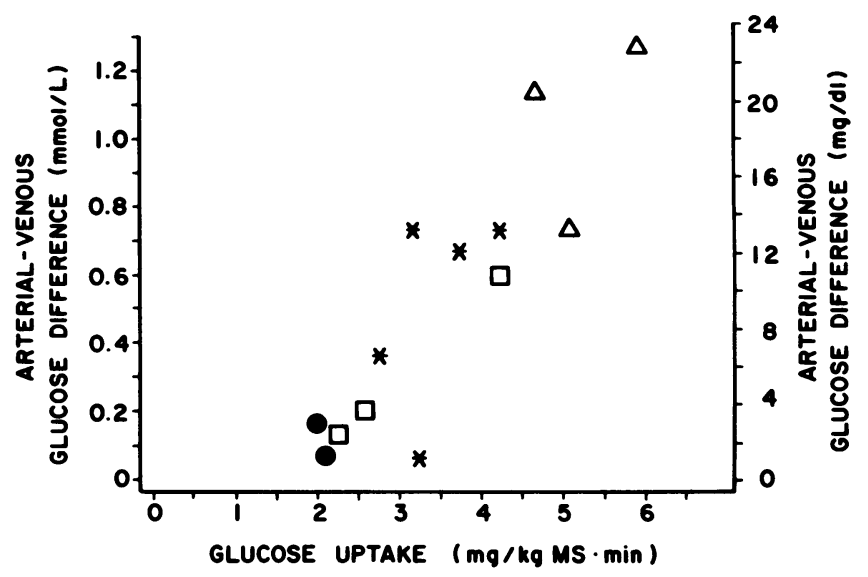

Figure 4. Mean arteriovenous glucose difference ( $\mathrm{mmol} /$ liter) and mean glucose uptake rate over $150 \mathrm{~min}$ of insulin infusion $(r=0.88$, $P \leq 0.0001$ ) (symbols defined in Fig. 3). $x$-axis intercept (zero lower limb glucose uptake) $=1.69 \mathrm{mg} / \mathrm{kg}$ MS per min. Since studies were performed at $\sim 100 \mathrm{mg} / \mathrm{dl}(99.2 \mathrm{mg} / \mathrm{dl}$; range, $96-107 \mathrm{mg} / \mathrm{dl})$, the $\mathrm{A}-\mathrm{V}$ difference (in $\mathrm{mg} / \mathrm{dl}$; right-hand scale) is approximately equal to a percent $\mathrm{A}-\mathrm{V}$ difference. Low $\mathrm{A}-\mathrm{V}$ differences indicate that substrate uptake is limited by the rate of diffusion ("diffusion limitation") (47, 48). When much of the substrate in the artery disappears before reaching the vein then the uptake of the substrate is predominantly limited by the amount presented to the tissue by blood flow ("flow limitation") $(47,48)$. Increased flow rates alone across the limb are only effective if extraction (percent AV difference) is high; therefore, insulin-sensitive subjects will benefit the most from changes in blood flow alone. This might indicate that low blood flow responses to insulin infusions $(45,46)$ are themselves an effect of insulin resistance. 
those with little whole body glucose uptake have small A-V differences. With a constant arterial blood glucose the A-V difference of glucose across the lower limb in an individual depends on the glucose diffusion gradient from the interior of capillaries to cells (due to insulin), and the rate at which glucose-rich blood is supplied to the limb. If blood flow is low and glucose consumption is high, then a large A-V difference is created ("flow limited" uptake $[47,48]$ ). If, in contrast, blood flow is high and glucose consumption is low, further increases in blood flow are only wasteful since apparently little glucose is needed ("diffusion limited" uptake $[47,48]$ ). In this situation an increase in blood flow alone merely results in a further drop in the A-V difference, not an increase in tissue glucose uptake. It can be seen from Fig. 4 that only the lean, insulin-sensitive subjects have a sufficiently large A-V difference such that increases in blood flow alone will increase glucose uptake significantly.

In those subjects with insulin resistance and a low $\mathrm{A}-\mathrm{V}$ difference of glucose an increase in the number of capillaries perfused should result in some improvement of glucose uptake by increasing tissue insulinization and by increasing the capillary surface area for glucose diffusion (49). There was, however, no relationship between the percent A-V difference in insulin across the lower limb and obesity. This indicates that insulin diffusion in the lower limb in the obese is not reduced relative to lean subjects, consistent with the lymph studies, and an increase in blood flow in obese individuals might not be any more beneficial to them than to the lean subjects in respect to tissue insulinization. We conclude from the facts that flow is more limiting in the lean subjects, that interstitial insulin is not reduced in the most obese, and that cellular insulin resistance is implied by the low coupling between glucose and lymph insulins that it is likely the low limb blood flows in obese individuals are not a cause of their insulin resistance but rather an effect of insulin resistance that prevents the wasteful direction of cardiac output to tissues where blood flow is already supplying glucose well.

Glucose uptake did not necessarily reach plateaus in this study, therefore, the half-times of activation are difficult to assess, likewise, we cannot assess half-times of activation of tissue insulin concentrations and especially so since the appearance of lymph at the skin appeared to lag behind its action in the tissues. Therefore, we are not able to address the issues of whether in obese subjects the delay in insulin activation of glucose found by Prager et al. (16) and Doeden and Rizza (17) might be due to delay in insulin penetration into tissues, or due to factors at, or in, the muscle cells.

The correlation of glucose uptake and capillary density (4) may require other explanations than those previously proposed $(4,13)$. The answer may lie in the biochemical properties that accompany differences in capillary density and muscle fiber type. Human skeletal muscle is composed of mixed fiber types. Fiber types are determined by the histological staining properties of myosin ATPases. These staining characteristics are determined by myosin biochemical structure and are associated with different reaction speeds, which determine the cell twitch characteristics (50-52). These histological properties also reflect the coordinated cellular expression of multiple other enzymes $(53,54)$. A greater density of capillary supply is found in type I muscle fibers $(55,56$, compare reference 57$)$, which are oxidative, slow twitch (50-52), and more insulin sensitive ( 58 ,
59). Type IIB fibers are at the opposite physiological extreme of type I fibers. The real correlation of capillary supply appears to be with muscle cell mitochondrial content (55), and the correlation of capillary density with fiber type is due to the association of fiber type with mitochondrial content. It is possible, therefore, that glucose uptake is associated with muscle cell biochemical properties, of which myofibrillar ATPase and capillary density are only markers.

In conclusion, insulin concentration changes in arterial blood in man are followed by changes in lymphatic insulin concentrations that are both delayed and reduced. It is these latter concentrations that determine in vivo insulin action in each individual, however, and explain why insulin action is delayed relative to changes in arterial insulin. Differences in insulin action between lean and obese subjects are not due to the rate of insulin delivery to the interstitium, but are determined by tissue factors, as demonstrated by the reduced coupling of glucose uptake and interstitial insulin.

\section{References}

1. Randle. P. J.. P. B. Garland, C. N. Hales, and E. A. Newsholme. 1963. The glucose fatty-acid cycle: its role in insulin sensitivity and the metabolic disturbances of diabetes mellitus. Lancet. i:785-789.

2. Lillioja, S., C. Bogardus, D. M. Mott, A. L. Kennedy, W. C. Knowler, and B. V. Howard. 1985. Relationship between insulin-mediated glucose disposal and lipid metabolism in man. J. Clin. Invest. 75:1106-1115.

3. Felber, J. P., R. Munger, E. Temler, D. Jallut, P. Frascarolo, and E. Jequier. 1991. Effect of lipid infusion on glycogen synthase and phosphorylase in muscle biopsies in man: Suggestion of a physiological mechanism regulating glucose storage. Diabetes. 40(Suppl. 1):258a. (Abstr.)

4. Lillioja, S., A. A. Young. C. L. Cutler, J. L. Ivy, W. G. H. Abbott, J. K Zawadzki. H. Yki-Jarvinen, L. Christin, T. W. Secomb, and C. Bogardus. 1987. Skeletal muscle capillary density and fiber type are possible determinants of in vivo insulin resistance in man. $J$. Clin. Invest. 80:415-424.

5. Lillioja, S., D. M. Mott, J. K. Zawadzki, A. A. Young. W. G. Abbott, and C. Bogardus. 1986. Glucose storage is a major determinant of in vivo "insulin resistance" in subjects with normal glucose tolerance. J. Clin. Endocrinol. \& Metab. 62:922-927.

6. Borkman. M.. L. H. Storlien, D. A. Pan, J. A. Sowden, D. J. Chisholm, and L. V. Campbell. 1991. Skeletal muscle triglyceride content and membrane unsaturation are related to fasting plasma insulin in patients with coronary artery disease. Diabetes. 40(Suppl. 1):245a. (Abstr.)

7. Storlien, L. H.. A. B. Jenkins, D. J. Chisholm, W. S. Pascoe. S. Khouri, and E. W. Kraegen. 1991. Influence of dietary fat composition on development of insulin resistance in rats. Relationship to muscle triglyceride and omega-3 fatty acid in muscle phospholipid. Diabetes. 40:280-289.

8. Johnson, K. H., T. D. O’Brien, C. Betsholtz, and P. Westermark. 1989. Islet amyloid, islet-amyloid polypeptide, and diabetes mellitus. N. Engl. J. Med. 321:513-518.

9. Leighton. B., and G. J. Cooper. 1988. Pancreatic amylin and calcitonin gene-related peptide cause resistance to insulin in skeletal muscle in vitro. Nature (Lond.). 335:632-635.

10. Rasio, E. A., E. Mack, R. H. Egdahl, and M. G. Herrera. 1968. Passage of insulin and insulin across vascular membranes in the dog. Diabetes. 17:668-672.

11. Camu, F., and E. Rasio. 1972. Peripheral glucose uptake in relation to physiological levels of plasma and lymph insulin. Eur. J. Clin. Invest. 2:188-194.

12. Rasio E. 1982. The capillary barrier to circulating insulin. Diabetes Care. 5:158-161.

13. Lillioja, S., and C. Bogardus. 1988. Obesity and insulin resistance: lessons learned from the Pima Indians. Diab. Metab. Rev. 4:517-540.

14. Yang, Y. J., I. D. Hope, M. Ader, and R. N. Bergman. 1989. Insulin transport across capillaries is rate limiting for insulin action in dogs. J. Clin. Invest. $84: 1620-1628$.

15. Sherwin, R. S., K. J. Kramer, J. D. Tobin, P. A. Insel, J. E. Liljenquist, M. Berman, and R. Andres. 1974. A model of the kinetics of insulin in man. J. Clin. Invest. 53:1481-1492.

16. Prager, R., P. Wallace, and J. M. Olefsky. 1986. In vivo kinetics of insulin action on peripheral glucose disposal and hepatic glucose output in normal and obese subjects. J. Clin. Invest. 78:472-481.

17. Doeden. B., and R. Rizza. 1987. Use of a variable insulin infusion to assess 
insulin action in obesity: defects in both the kinetics and amplitude of the response. J. Clin. Endocrinol. \& Metab. 64:902-908.

18. McGuire, E. A., J. D. Tobin, M. Berman, and R. Andres. 1979. Kinetics of native insulin in diabetic, obese and aged men. Diabetes. 28:110-120.

19. Castillo, C. E., and S. Lillioja. 1991. Peripheral lymphatic cannulation for physiological analysis of interstitial fluid compartment in humans. Am. J. Phys iol. 216:H1324-H1328.

20. Bennett, P. H. 1983. The diagnosis of diabetes: new international classification and diagnostic criteria. Annu. Rev. Med. 34:295-309.

21. Goldman, R. F., and E. R. Buskirk. 1961. Body volume measurement by underwater weighing. In Techniques for Measuring Body Composition. J. Brozek and A. Henschel, editors. National Academy of Sciences, National Research Council, Washington, DC. 78-106.

22. Keys, A., and J. Brozek. 1953. Body fat in adult man. Physiol. Rev 33:245-325.

23. Olszewski, W. L., and A. Engeset. 1980. Intrinsic contractility of prenoda lymph vessels and lymph flow in human leg. Am. J. Physiol. 239:H775-H783.

24. Olszewski, W., A. Engeset, P. M. Jaeger, J. Sokolowski, and L. Theodorsen. 1977. Flow and composition of leg lymph in normal men during venous stasis, muscular activity and local hyperthermia. Acta Physiol. Scand. 99:149155 .

25. DeFronzo, R. A., J. D. Tobin, and R. Andres. 1979. Glucose clamp technique: a method for quantifying insulin secretion and resistance. Am. J. Physiol. 237:E214-E223.

26. Finegood, D. T., R. N. Bergman, M. Vranic. 1987. Estimation of endogenous glucose production during hyperinsulinemic: euglycemic clamps. Diabetes. 36:914-924.

27. Bergman, R. N., I. D. Hope, Y. J. Yang, R. M. Watanabe, M. A. Meador, J. H. Youn, and M. Ader. 1989. Assessment of insulin sensitivity in vivo: a critical review. Diabetes Metab. Rev. 5:411-429.

28. Best, J. D., J. G. Judzewitsch, M. A. Pfeifer, J. C. Beard, J. B. Halter, and D. Porte, Jr. 1982. The effect of chronic sulfonylurea therapy on hepatic glucose production in non-insulin dependent diabetes. Diabetes. 31:333-338.

29. Yki-Jarvinen, H., A. Consoli, N. Nurjhan, A. A. Young, and J. E. Gerich. 1989. Mechanism for underestimation of isotopically determined glucose disposal. Diabetes. 38:744-751.

30. Neter, J., and W. Wasserman. 1974. Applied linear statistical models. Regression, Analysis of Variance, and Experimental Design. Richard D. Irwin, Inc. Homewood, IL. 313-317.

31. Majno, G. 1965. Ultrastructure of the vascular membrane. In Handbook of Physiology. Circulation. W. F. Hamilton, editor. American Physiological Society, Washington, DC. Section 2. Vol. III. 2293-2375.

32. Crone, C., and D. G. Levitt. 1984. Capillary permeability to small solutes. In Handbook of Physiology. The Cardiovascular System. E. M. Renkin and C. C. Michel, editors. American Physiological Society, Bethesda, MD. Section 2. Vol. IV, part I. 411-466.

33. Michel, C. C. 1988. Capillary permeability and how it may change. $J$. Physiol. 404:1-29.

34. Curry, F. E., W. L. Joyner, and J. C. Rutledge. 1990. Graded modulation of frog microvessel permeability to albumen using ionophore A23187. Am. J. Physiol. 258:H587-H598.

35. Watson, P. D. 1980. The interstitial matrix as a barrier in blood-to-lymph solute movement. Physiologist. 23:86-89.

36. King, G. L., and S. M. Johnson. 1985. Receptor-mediated transport of insulin across endothelial cells. Science (Wash. DC). 227:1583-1586.

37. Hilsted, J., and N. J. Christensen. 1992. Dual effect of insulin on plasma volume and transcapillary albumen transport. Diabetologia. 35:99-103.

38. Bogardus, C., and S. Lillioja. 1990. Where all the glucose doesn't go in non-insulin-dependent diabetes mellitus. N. Engl. J. Med. 322:262-263.

39. Skalak, T. C., G. W. Schmid-Schonbein, and B. W. Zweifach. 1984. Microvasc. Res. 28:95-112.
40. Chernick, S. S., R. J. Gardiner, and R. O. Scow. 1987. Restricted passage of insulin across capillary endothelium in perfused rate adipose tissue. Am. J. Physiol. 253:E475-E480.

41. Weigle, D. S. 1987. Pulsatile secretion of fuel-regulatory hormones. Diabetes. 36:764-775.

42. Paolisso, G., A. J. Scheen, E. M. Verdin, A. S. Luychx, and P. J. Lefebvre. 1986. Insulin oscillation per se do not affect glucose turnover parameters in normal man. J. Clin. Endocrinol. \& Metab. 63:520-525.

43. Bratusch-Marrain, P. R., M. Komjati, and W. K. Waldhausl. 1986. Efficacy of pulsatile versus continuous insulin administration on hepatic glucose production and glucose utilization in type-1 diabetic humans. Diabetes. 35:922926

44. Komjati, M., H. Astner-Kremsmayr, W. Waldhausl, W. Reitgruber, F. Breitenecker, and I. Troch. 1988. Interaction of sympathomimetics and insulin with hepatic glucose production by isolated perfused rat livers. Effects of continuous versus pulsatile infusion. Endocrinology. 123:1798-1807.

45. Laasko, M., S. V. Edelman, G. Brechtel, and A. D. Baron. 1990. Decreased effect of insulin to stimulate skeletal muscle blood flow in obese man. $J$. Clin. Invest. 85:1844-1852.

46. Baron, A. D., M. Laasko, G. Brechtel, and S. V. Edelman. 1991. Reduced capacity and affinity of skeletal muscle for insulin-mediated glucose uptake in non-insulin dependent diabetic subjects. J. Clin. Invest. 87:1186-1194.

47. Michel, C. C. 1972. Flows across the capillary wall. In Cardiovascular Fluid Dynamics. D. H. Bergel, editor. Academic Press Limited, London. 269274.

48. Caro, C. G., T. J. Pedley, R. C. Schroter, and W. A. Seed. 1978. The Mechanics of the Circulation. Oxford University Press, Oxford. 416-429.

49. Renkin, E. M. 1989. Control of microcirculation and blood-tissue exchange. In Handbook of Physiology. The Cardiovascular System, E. M. Renkin and C. C. Michel, editors. American Physiological Society, Bethesda, MD. Section 2. Vol. IV, part 2. 630-642.

50. Eisenburg, B. R. 1983. Quantitative ultrastructure of mammalian skeletal muscle. In Handbook of Physiology. Skeletal Muscle. L. D. Peachey, editor. American Physiological Society, Bethesda, MD. Section 10. 73-111.

51. Saltin, B., and P. D. Gollnick. 1983. Skeletal muscle adaptability: significance of metabolism and performance. In Handbook of Physiology. Skeletal Muscle. L. D. Peachey, editor, American Physiological Society, Bethesda, MD. Section 10. 555-631.

52. Thomason, D. B., K. M. Baldwin, and R. E. Herrick. 1986. Myosin isozyme distribution in rodent hindlimb skeletal muscle. J. Appl. Physiol. 60:19231931

53. Lowry, C. V., J. S. Kimmey, S. Felder, M. M-Y. Chi, K. K. Kaiser, P. N. Passonneau, K. A. Kirk, and O. H. Lowry. 1978. Enzyme patterns in single human muscle-fibers. J. Biol. Chem. 253:8269-8277.

54. Peter, J. B., R. J. Barnard, V. R. Edgerton, C. A. Gillespie, and K. E. Stempel. 1972. Metabolic profiles of three fiber types of skeletal muscle in guinea pigs and rabbits. Biochemistry. 11:2627-2633.

55. Ingjer, F. 1979. Effects of endurance training on muscle fibre ATPase activity, capillary supply and mitochondrial content in man. J. Physiol. (Lond.). 294:419-432.

56. Andersen, P., and J. Henriksson. 1977. Capillary supply of the quadriceps femoris muscle of man: adaptive response to exercise. J. Physiol. (Lond.) 270:677-690.

57. Tesch, P. A., A. Thorsson, and P. Kaiser. 1984. Muscle capillary supply and fiber type characteristics in weight and power lifters. J. Appl. Physiol. 56:3538.

58. Hom, F. G., and Goodner, C. J. 1984. Insulin dose-response characteristics among individual muscle and adipose tissues measured in the rat in vivo with ${ }^{3}$ (H)2-deoxyglucose. Diabetes. 33:153-159.

59. James, D. E., A. B. Jenkins, and E. W. Kraegen. 1985. Heterogeneity of insulin action in individual muscles in vivo: euglycemic clamp studies in rats. Am. J. Physiol. 248:E567-E574. 